\title{
Indução de variabilidade na cultivar de arroz Metica-1 para resistência a Pyricularia grisea $^{(1)}$
}

\author{
Leila Garcês de Araújo(2) e Anne Sitarama Prabhu(2)
}

\begin{abstract}
Resumo - A brusone é um dos fatores limitantes da produtividade da cultivar Metica-1, no Estado do Tocantins. Objetivando obter somaclones resistentes, foi realizada a indução de calos e a regeneração de plantas a partir de panículas imaturas da cultivar Metica-1. Duzentas e oitenta plantas $\mathrm{R}_{2}$ foram submetidas a inoculação inóculo de patótipos de Pyricularia grisea, ID-14 e II-1, provenientes das cultivares Metica-1 e Cica-8, respectivamente. Enquanto todas as 280 plantas $\mathrm{R}_{2}$ de Metica-1 foram resistentes em relação ao patótipo II-1, as progênies de duas plantas $R_{1}$ mostraram resistência ao patótipo ID-14, indicando a indução de variação genética com relação à resistência à brusone na cultivar suscetível, nas gerações iniciais. A geração $R_{3}$ foi avançada e entre 280 somaclones $R_{4}$ foram selecionados 51 , incluindo dois somaclones, CNAI10390 e CNAI10393, que mostraram resistência vertical no viveiro de brusone. Nas gerações avançadas de $R_{5}$ e $R_{6}$, estes dois somaclones apresentaram resistência no viveiro e nas inoculações com cinco isolados, provenientes das cultivares Metica-1, Cica-8 e Epagri 108, e poderão ser usados como novas fontes de resistência à brusone nos programas de melhoramento de arroz.
\end{abstract}

Termos para indexação: Oryza sativa, brusone, variação somaclonal, variação genética, melhoramento de plantas.

\section{Induction of variability for resistance in the rice cultivar Metica-1 to Pyricularia grisea}

\begin{abstract}
Rice blast is one of the yield limiting factors of the rice cultivar Metica-1, in the State of Tocantins, Brazil. Plants of this cultivar were regenerated from the callus cultures derived from immature panicles with the objective of obtaining blast resistant somaclones. Two hundred eighty $\mathrm{R}_{2}$ plants were assessed utilizing pathotypes ID-14 and II-1 of Pyricularia grisea, retrieved from the cultivars Metica-1 and Cica- 8 , respectively. While all $\mathrm{R}_{2}$ plants of the cultivar Metica- 1 were resistant to the pathotype II-1, the progenies of two $R_{1}$ plants showed resistance to pathotype ID-14, indicating thereby the induction of genetic variation for blast resistance in the susceptible rice cultivar, in early generations. The $\mathrm{R}_{3}$ generation was advanced, and of 280 somaclones in $\mathrm{R}_{4}$ generation, 51 were selected including two somaclones CNAI10390 and CNAI10393, which exhibited vertical resistance, in blast nursery. In the advanced $R_{5}$ and $R_{6}$ generations, these two somaclones showed resistant reaction in blast nursery test, as well as in inoculation tests with the isolates from the cultivars Metica-1, Cica-8 and Epagri 108, and can be used as new blast resistant sources in rice breeding programs.
\end{abstract}

Index terms: Oryza sativa, rice blast, somaclonal variation, genetic variation, plant breeding.

\section{Introdução}

A brusone, cujo agente causal é o fungo Pyricularia grisea (Cooke) Saccardo [= Magnaporthe grisea (Hebert) Barr] constitui principal fator biótico limitante da produtividade do arroz irrigado no

\footnotetext{
(1) Aceito para publicação em 22 de agosto de 2002.

(2) Embrapa-Centro Nacional de Pesquisa de Arroz e Feijão, Caixa Postal 179, CEP 75375-000 Santo Antônio de Goiás, GO. Bolsista do CNPq. E-mail: leilag@cnpaf.embrapa.br, prabhu@cnpaf.embrapa.br
}

Estado do Tocantins, onde a cultivar Metica-1 é plantada anualmente em extensas áreas. 'Metica-1' foi desenvolvida pelo Centro Internacional de Agricultura Tropical (CIAT) e pelo Instituto Colombiano do Arroz (ICA), por cruzamentos múltiplos envolvendo as cultivares/linhagens IR 930-53, IR 579-160, IR 22, IR 930-147-8, IR 930-31-10, IR 662 e Colômbia-1, sendo introduzida no Brasil em 1981, pela EmbrapaCentro Nacional de Pesquisa de Arroz e Feijão (CNPAF). Essa cultivar mostrou moderada suscetibilidade à brusone nas folhas e panículas quando foi lançada, em 1986, para cultivo em condi- 
ções irrigadas no Brasil (Prabhu \& Ferreira, 1991) Tal suscetibilidade aumentou ao longo dos anos, resultando em perdas significativas de produtividade. Mas por causa do seu potencial produtivo, permanece como uma das cultivares preferidas pelos produtores.

O melhoramento do arroz irrigado quanto à resistência à brusone é uma das prioridades da pesquisa agrícola nacional; até o momento foram lançadas as cultivares Javaé e Rio Formoso, com alto grau de resistência. A durabilidade da resistência dessas cultivares tem sido limitada por causa da alta variabilidade do patógeno. A base genética das cultivares lançadas é estreita (Cuevas-Pérez et al., 1992) e as fontes de resistência utilizadas são limitadas a poucos genótipos. A indução de variabilidade com relação à resistência a doenças nas cultivares suscetíveis, altamente produtivas e de boa qualidade de grãos, é uma das alternativas na obtenção de novas fontes com amplo espectro de resistência.

A cultura de tecidos é uma das ferramentas na indução de variabilidade genética nas plantas (Evans et al., 1984; Duval et al., 1998). A vantagem da indução de variabilidade por meio dessa técnica é sua capacidade de produzir em curto prazo um grande número de plantas que diferem somente em uma determinada característica, como resistência a doenças (Evans et al., 1984; Chauhan et al., 1996), ciclo, tipo de grão e produtividade (Rueb et al., 1994). Essas alterações não são drásticas em relação à arquitetura da planta, como no caso da mutagênese convencional (Chopra et al., 1989). As variações genéticas das plantas de arroz regeneradas a partir de calos são herdáveis e ocorrem em características monogênicas e poligênicas (Mandal et al., 2000).

No Brasil, alguns estudos mostraram sucesso na obtenção de somaclones com resistência vertical e parcial à brusone a partir de cultivares suscetíveis de arroz, como IAC 47, Araguaia, Bluebelle e Basmati-370 (Araújo et al., 1997, 1998, 2000, 2001a, 2001b; Araújo \& Prabhu, 2001). Também foram obtidos somaclones de IAC 47 com diferentes graus de resistência parcial à escaldadura (Araújo et al., 2001c). Os estudos de herança da resistência dos somaclones da cultivar Araguaia mostraram que um gene dominante e designado $P i$-ar controla a resistência ao patótipo IB-45 de P. grisea (Araújo et al., 1999).
A recuperação de caraterísticas estáveis e herdáveis com relação à resistência à brusone e outras características agronômicas a partir de cultivares suscetíveis fizeram com que se incluíssem nos estudos outras cultivares de importância agrícola.

O presente estudo objetivou a indução de variabilidade genética para resistência à brusone na cultivar Metica-1 suscetível, pela técnica da variação somaclonal.

\section{Material e Métodos}

A indução de calos e regeneração de plantas a partir da cultivar Metica-1 foram realizadas de acordo com Araújo et al. (1998). As plantas regeneradas foram referidas como geração $R_{1}$ e as gerações subseqüentes como $R_{2}$ a $R_{6}$ (Araújo \& Prabhu, 2001).

As 280 plantas $R_{2}$ obtidas de 14 plantas $R_{1}$ individuais e as cultivares Metica-1 e Cica-8 foram avaliadas quanto à resistência a dois isolados de $P$. grisea. Foram utilizados um isolado obtido de lesões foliares da cultivar Metica-1 (MtPy-Py1125) da Estação Experimental do Formoso, localizada em Formoso do Araguaia, TO, em 1997, e o outro, de lesões foliares da cultivar Cica-8 (CiPy-436) da Estação Experimental Palmital, localizada em Brazabrantes, GO, em 1995. O experimento foi realizado em casa de vegetação, em bandejas (30x10x15 cm) contendo $3 \mathrm{~kg}$ de solo, adubado por ocasião do plantio com $5 \mathrm{~g}$ de NPK (4-30-16), $1 \mathrm{~g}$ de sulfato de zinco e $2 \mathrm{~g}$ de sulfato de amônio. Foi feita uma adubação de cobertura, 20 dias após a semeadura, com $2 \mathrm{~g}$ de sulfato de amônio por bandeja. O delineamento usado foi o de blocos ao acaso com três repetições e em esquema de parcelas subdivididas. As parcelas principais consistiram dos isolados e as subparcelas, dos genótipos. Os genótipos consistiram da progênie $R_{2}$, das 14 plantas $R_{1}$ e das cultivares Metica- $1 \mathrm{e}$ Cica-8. Cada bandeja continha oito sulcos de $10 \mathrm{~cm}$ com oito genótipos, totalizando 12 bandejas. Cerca de 25 sementes de cada planta $\mathrm{R}_{1}$ foram semeadas por sulco. Em outra bandeja foram semeadas oito cultivares diferenciadoras internacionais, as quais receberam inóculo de cada um dos isolados para a identificação dos patótipos.

A inoculação ocorreu aos 22 dias de idade das plantas, conforme Prabhu et al. (1992). As avaliações da brusone nas folhas foram feitas sete a nove dias após a inoculação, utilizando a escala visual de notas variando de 0-9 (Leung et al., 1988), em que 0-3: resistência (completa ou vertical) e 4-9: reação de suscetibilidade. As plantas $R_{2}$ resistentes em relação ao isolado de Cica-8, incluindo duas plantas também resistentes ao isolado de Metica-1, foram trans- 
plantadas para o campo (linhas de 2,0 m de comprimento), em condições de várzea úmida (solo Gley Húmico), para colheita das sementes das plantas $\mathrm{R}_{2}$ individuais. A geração $R_{3}$ foi avançada em agosto de 1998, em Formoso do Araguaia, em condições de várzea úmida. Foram utilizados a mesma adubação e tratos culturais de $\mathrm{R}_{2}$. Procedeu-se a colheita massal de 20 plantas para cada somaclone.

Os 280 somaclones $\mathrm{R}_{4}$ de Metica-1 e a cultivar Metica-1 foram avaliados em viveiro de brusone, estabelecido no campo para obtenção de alta pressão de seleção. $A$ adubação foi a mesma utilizada em $R_{2}$. Foram utilizadas linhas de 0,5 $\mathrm{m}$ de comprimento, com espaçamento de $0,10 \mathrm{~m}$ e densidade de semeadura de 200 sementes $/ \mathrm{m}$ linear. Uma bordadura composta pela mistura de cultivares suscetíveis foi estabelecida 30 dias antes do plantio a fim de induzir a epidemia da doença. A avaliação da brusone foi realizada aos 34 dias após o plantio mediante escala visual de notas que variou de 0-9 (International Rice Research Institute, 1988). Dos 280 somaclones $\mathrm{R}_{4}$ avaliados selecionaram-se 51, cujas sementes foram colhidas em bulk de 20 plantas para cada somaclone $\mathrm{R}_{4}$.

Na geração $R_{5}$, os 51 somaclones de Metica-1 e a cultivar Metica-1 foram avaliados novamente no viveiro de brusone, utilizando-se a mesma metodologia da geração $\mathrm{R}_{4}$. Nesta geração a severidade de brusone expressa em porcentagem de área foliar afetada foi determinada em três folhas superiores completamente abertas, de cinco perfilhos principais de cada planta, 39 dias após o plantio. Utilizouse uma escala de 11 graus modificada de Notteghem (1981). Foram selecionados 38 somaclones com diferentes graus de resistência (nota 1) e suscetibilidade (notas 6, 7, 8 e 9), os quais foram transplantados para vasos de $6 \mathrm{~kg}$ de solo, em casa de vegetação, para colheita de sementes.

A geração $R_{6}$ foi avaliada de três maneiras. Uma parte das sementes foi usada na avaliação da resistência dos 38 somaclones e da cultivar Metica-1, no viveiro de brusone, da mesma forma que na geração $R_{5}$. A correlação entre a severidade de brusone nas folhas entre as duas gerações $R_{5}$ e $R_{6}$ foi analisada. Outra parte das sementes foi usada para avaliar o grau de resistência dos mesmos genótipos nos cinco isolados de $P$. grisea, em condições de casa de vegetação. Esses isolados incluíram um obtido da cultivar Metica-1 e um de Cica-8 utilizados em $\mathrm{R}_{2}$, dois isolados dos somaclones, um de Metica-1 (ScmetPy) e outro de Cica-8 (SccicaPy), que apresentaram notas visuais 6 e 5, respectivamente, na Estação Experimental Palmital da Embrapa-CNPAF, e um da cultivar Epagri 108 (EpPy). Por último, os mesmos somaclones foram avaliados no campo em relação à mancha-dos-grãos, ciclo e peso de grãos. O delineamento experimental foi o de blocos com- pletos casualizados, com três repetições. Aplicaram-se $250 \mathrm{~kg} / \mathrm{ha}$ da fórmula 4-30-16, $125 \mathrm{~kg} / \mathrm{ha}$ de sulfato de amônio e $20 \mathrm{~kg} / \mathrm{ha}$ de sulfato de zinco, no sulco, por ocasião do plantio. Utilizou-se o espaçamento de $0,20 \mathrm{~m} \mathrm{e}$ uma densidade de semeadura de 80 sementes $/ \mathrm{m}$. Cada parcela constituiu-se de uma linha de $2,0 \mathrm{~m}$. Avaliou-se a duração do ciclo, a severidade da mancha-dos-grãos (Dreschslera oryzae, Phoma sorghina, Alternaria padwickii, Pyricularia grisea, Microdochium oryzae, Sarocladium oryzae) e o peso de 100 grãos.

Uma amostra de 100 grãos colhidos de dez panículas foi usada na avaliação da severidade da mancha-dos-grãos e no peso de 100 grãos. Na avaliação da severidade da mancha-dos-grãos, utilizou-se a escala de quatro graus de Prabhu \& Ferreira (1991), em que 0: sem sintomas; 1: pequenas manchas com tamanho da cabeça de um alfinete; 2: $25 \%$ de grãos com superfície descolorida e $4: \geq 50 \%$ de grãos com superfície descolorida. A severidade da mancha-dos-grãos (SMG) foi calculada a partir da fórmula:

$\operatorname{SMG}(\%)=\frac{\sum \text { valor da classe } \mathrm{x} \text { freqüência } \mathrm{x} 100}{\text { Número total de grãos } \mathrm{x} 4}$

Foi estudada também a correlação entre a severidade da mancha-dos-grãos e o peso de 100 grãos.

\section{Resultados e Discussão}

De um total de 280 plantas $\mathrm{R}_{2}$ da cultivar Metica-1, provenientes de 14 plantas $R_{1}$ avaliadas em relação ao patótipo ID-14, somente as progênies de duas plantas $R_{1}$ apresentaram reação de resistência (nota 3). Por sua vez, a cultivar Metica-1 permaneceu altamente suscetível à brusone (nota 9) nas folhas. Todas as 280 plantas $R_{2}$ e a cultivar Metica- 1 apresentaram reação de resistência (nota 1) com relação ao patótipo II-1. As plantas $\mathrm{R}_{2}$ resistentes ao patótipo II-1 foram avançadas na geração $R_{3}$.

Dos 280 somaclones $\mathrm{R}_{4}$, somente dois apresentaram reação de resistência, com nota 3 , enquanto a cultivar Metica-1 mostrou reação altamente suscetível (nota 9) nas mesmas condições (Figura 1). Esses dois somaclones são os mesmos que apresentaram resistência na geração $\mathrm{R}_{2}$, demonstrando a estabilidade da resistência.

$\mathrm{Na}$ geração $\mathrm{R}_{5}$, entre 52 genótipos avaliados no viveiro, incluindo Metica-1, somente dois somaclones (CNAI10390 e CNAI10393) continuaram apresentando resistência à brusone (nota 1), enquan- 
to a cultivar Metica-1 apresentou reação altamente suscetível (Tabela 1). Resultados semelhantes com alto a moderado grau de resistência à brusone foram relatados em outros países por Bouharmont et al. (1991) e Chauhan et al. (1996). No Brasil, foram obtidos somaclones com resistência vertical a partir das cultivares suscetíveis Araguaia e Bluebelle (Araújo et al., 2000; 2001b). A variação genética nas plantas regeneradas é por causa da variação preexistente no explante doador e no meio de cultura. As alterações no genoma foram atribuídas à expressão de células mutantes, recombinação mitótica e outras variações citológicas (Evans et al., 1984). Quanto à severidade da brusone nas folhas, 13 somaclones apresentaram valores relativamente menores do que a cultivar Metica-1.

Em $\mathrm{R}_{6}$, a resistência dos dois somaclones no viveiro de brusone foi mantida. Entre 38 somaclones avaliados, somente sete (CNAI10390, CNAI10391, CNAI10393, CNAI10397, CNAI10398, CNAI10406e CNAI10427) apresentaram severidades menores do que a cultivar Metica-1 (Tabela 1). A correlação dos valores de severidade entre somaclones das gerações $\mathrm{R}_{5}$ e $\mathrm{R}_{6}$ foi significativa $\left(\mathrm{r}=0,85^{* *}\right)$. Este resultado revelou a estabilidade quanto ao grau de resistência da brusone nas folhas nas duas gerações.

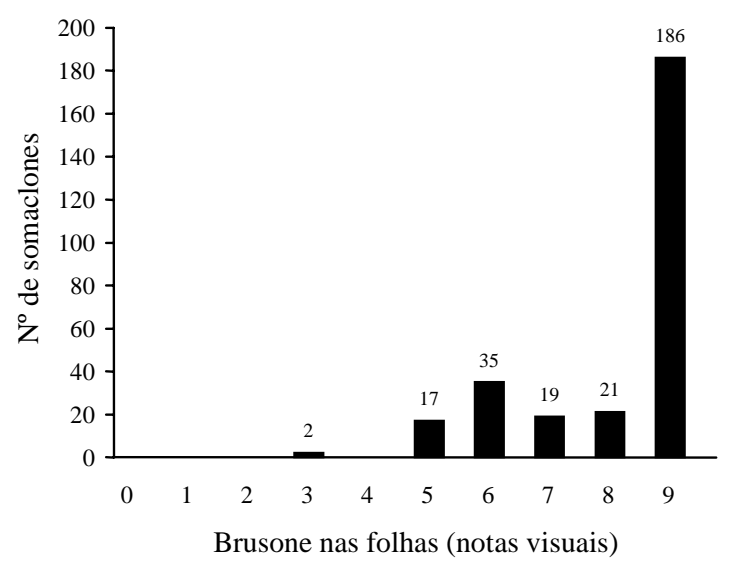

Figura 1. Distribuição de somaclones $R_{4}$ da cultivar Metica-1 de acordo com a reação à brusone (notas visuais: 0-3: resistência completa ou vertical; 4-9: reação de suscetibilidade) nas folhas de arroz em viveiro de brusone. A cultivar Metica-1 utilizada como testemunha suscetível apresentou reação altamente suscetível, nota 9.
Os dois somaclones resistentes à brusone também apresentaram ciclo precoce no campo, em Santo Antônio de Goiás, GO, com duração do ciclo de 120 dias contra 135 dias da cultivar Metica-1. Abbasi et al. (1999) também constataram redução expressiva no número de dias em relação ao florescimento e à altura das plantas.

Os dois somaclones resistentes no viveiro de brusone também foram resistentes quanto aos cinco isolados do patógeno utilizado (Tabela 1). Entre os 38 somaclones $\mathrm{R}_{6}$ avaliados, oito, seis, cinco e sete foram resistentes em relação aos patótipos ID-14, IB-1, IB-1 e IB-45, de P. grisea, respectivamente, ao passo que a cultivar Metica-1 foi suscetível a todos os patótipos citados. Todos os somaclones apresentaram-se resistentes ao patótipo II-1, assim como a cultivar Metica-1. Filippi et al. (1999) também constataram que os isolados compatíveis com Cica-8 foram incompatíveis com a cultivar Metica-1. Por sua vez, 33 somaclones foram suscetíveis em relação ao isolado do somaclone de Cica-8, indicando mutação do gene quanto à suscetibilidade. As mutações nas diferentes características morfológicas das progênies de plantas de arroz foram obtidas e possivelmente ocorreram durante a fase de indução de calos ou regeneração de plantas (Fukui, 1983). O isolado de Metica-1 utilizado nas avaliações iniciais em $R_{2}$ foi compatível com a cultivar Metica-1, ao passo que os somaclones apresentaram reações diferenciais variando de 0 a 7, indicando indução de variabilidade genética com relação à brusone (Tabela 1). Os isolados provenientes dos somaclones de Metica-1 (ScmetPy3), de Cica-8 (SccicaPy12) e de Epagri 108 (EpPy) foram compatíveis com a cultivar Metica-1 e os somaclones apresentaram graus variáveis de resistência e de suscetibilidade.

A severidade da mancha-dos-grãos nos somaclones variou de $2,6 \%$ a $24,4 \%$. Entre os 38 somaclones, somente CNAI10401 apresentou severidade significativamente inferior aos demais, embora não tenha diferido da cultivar Metica-1, o que o indica como fonte de resistência à mancha-dos-grãos. A correlação entre a severidade da mancha-dosgrãos e o peso de 100 grãos foi linear e negativa, ou seja, o peso de 100 grãos diminuiu linearmente com o aumento do grau de severidade da mancha-dosgrãos nos somaclones (Figura 2). 
Tabela 1. Reação de somaclones $\mathrm{R}_{5}$ e $\mathrm{R}_{6}$ da cultivar de arroz Metica-1 no viveiro de brusone e de somaclones $\mathrm{R}_{6} \mathrm{em}$ relação a cinco isolados de Pyricularia grisea sob condições artificiais de inoculação em casa de vegetação, e severidade de mancha-dos-grãos (SMG) em somaclones $\mathrm{R}_{6}$ avaliados no campo.

\begin{tabular}{|c|c|c|c|c|c|c|c|c|c|c|}
\hline \multirow[t]{2}{*}{ Somaclone $^{(1)}$} & \multicolumn{4}{|c|}{ Viveiro de brusone } & \multicolumn{5}{|c|}{ Isolado $^{(4)}$} & \multirow[t]{2}{*}{ SMG $(\%)^{(5)}$} \\
\hline & $\begin{array}{c}\text { Ger } \\
\text { Nota }^{(2)}\end{array}$ & $\frac{\text { ação } \mathrm{R}_{5}}{\mathrm{SBF}(\%)^{(3)}}$ & $\frac{\mathrm{Ge}}{\mathrm{Nota}^{(2}}$ & $\frac{\operatorname{ação~} R_{6}}{\operatorname{SBF}(\%)^{(3)}}$ & $\mathrm{MtPy}$ & CiPy & ScmetPy3 & SccicaPy12 & EpPy & \\
\hline CNAI10390 & 1 & 0,0 & 1 & 0,0 & 1 & 0 & 1 & 3 & 0 & $11,1 \mathrm{abc}$ \\
\hline CNAI10391 & 6 & 17,9 & 7 & 34,0 & 0 & 0 & 5 & 7 & 0 & $24,4 \mathrm{a}$ \\
\hline CNAI10392 & 7 & 74,6 & 9 & 100,0 & 7 & 0 & 7 & 7 & 5 & $10,6 a b c$ \\
\hline CNAI10393 & 1 & 0,0 & 1 & 0,0 & 1 & 0 & 1 & 1 & 0 & $11,8 \mathrm{abc}$ \\
\hline CNAI10394 & 9 & 100,0 & 9 & 100,0 & 7 & 0 & 5 & 5 & 5 & $16,2 \mathrm{abc}$ \\
\hline CNAI10395 & 9 & 100,0 & 9 & 100,0 & 7 & 0 & 5 & 5 & 5 & $16,9 a b c$ \\
\hline CNAI10396 & 9 & 100,0 & 9 & 100,0 & 7 & 0 & 5 & 5 & 5 & $15,5 \mathrm{abc}$ \\
\hline CNAI10397 & 6 & 48,0 & 6 & 24,7 & 3 & 0 & 1 & 3 & 3 & $8,0 \mathrm{abc}$ \\
\hline CNAI10398 & 6 & 40,2 & 6 & 19,4 & 1 & 0 & 1 & 5 & 1 & $24,2 \mathrm{a}$ \\
\hline CNAI10399 & 7 & 87,4 & 9 & 100,0 & 7 & 0 & 5 & 5 & 5 & $12,8 \mathrm{abc}$ \\
\hline CNAI10400 & 7 & 69,4 & 9 & 100,0 & 7 & 0 & 5 & 5 & 5 & $16,8 \mathrm{abc}$ \\
\hline CNAI10401 & 7 & 47,0 & 9 & 100,0 & 5 & 0 & 5 & 5 & 5 & $14,4 \mathrm{abc}$ \\
\hline CNAI10402 & 7 & 65,6 & 9 & 100,0 & 9 & 0 & 5 & 7 & 5 & $14,3 \mathrm{abc}$ \\
\hline CNAI10403 & 7 & 88,6 & 9 & 100,0 & 9 & 0 & 5 & 5 & 5 & $13,6 a b c$ \\
\hline CNAI10404 & 7 & 67,6 & 9 & 100,0 & 7 & 0 & 5 & 7 & 5 & $18,3 \mathrm{abc}$ \\
\hline CNAI10405 & 7 & 89,2 & 9 & 100,0 & 7 & 0 & 5 & 7 & 5 & $14,6 a b c$ \\
\hline CNAI10406 & 7 & 65,2 & 7 & 25,0 & 7 & 0 & 5 & 7 & 5 & $2,6 \mathrm{c}$ \\
\hline CNAI10407 & 7 & 79,6 & 9 & 100,0 & 1 & 0 & 1 & 3 & 5 & $20,2 \mathrm{ab}$ \\
\hline CNAI10408 & 8 & 74,8 & 9 & 100,0 & 5 & 0 & 5 & 5 & 5 & $15,4 \mathrm{abc}$ \\
\hline CNAI10409 & 9 & 100,0 & 9 & 100,0 & 7 & 0 & 5 & 5 & 7 & $12,5 \mathrm{abc}$ \\
\hline CNAI10410 & 9 & 100,0 & 9 & 100,0 & 7 & 0 & 5 & 5 & 7 & $15,2 \mathrm{abc}$ \\
\hline CNAI10411 & 9 & 100,0 & 9 & 100,0 & 7 & 0 & 7 & 5 & 5 & $16,2 \mathrm{abc}$ \\
\hline CNAI10412 & 9 & 100,0 & 9 & 100,0 & 5 & 0 & 5 & 5 & 5 & $21,0 \mathrm{ab}$ \\
\hline CNAI10413 & 9 & 100,0 & 9 & 100,0 & 5 & 0 & 5 & 5 & 5 & $17,1 \mathrm{abc}$ \\
\hline CNAI10414 & 9 & 100,0 & 9 & 100,0 & 7 & 0 & 7 & 5 & 5 & $14,2 a b c$ \\
\hline CNAI10415 & 9 & 100,0 & 9 & 100,0 & 7 & 0 & 7 & 5 & 5 & $22,5 \mathrm{a}$ \\
\hline CNAI10416 & 8 & 100,0 & 9 & 100,0 & 7 & 0 & 5 & 5 & 5 & $16,7 \mathrm{abc}$ \\
\hline CNAI10417 & 9 & 100,0 & 9 & 100,0 & 5 & 0 & 5 & 5 & 7 & $18,1 \mathrm{abc}$ \\
\hline CNAI10418 & 9 & 100,0 & 9 & 100,0 & 5 & 0 & 5 & 5 & 5 & $12,7 \mathrm{abc}$ \\
\hline CNAI10419 & 9 & 100,0 & 9 & 100,0 & 5 & 0 & 7 & 5 & 5 & $15,8 \mathrm{abc}$ \\
\hline CNAI10420 & 9 & 100,0 & 9 & 100,0 & 5 & 0 & 5 & 5 & 5 & $18,2 \mathrm{abc}$ \\
\hline CNAI10421 & 9 & 100,0 & 9 & 100,0 & 5 & 0 & 5 & 5 & 5 & $14,4 a b c$ \\
\hline CNAI10422 & 9 & 100,0 & 9 & 100,0 & 7 & 0 & 7 & 7 & 5 & $15,4 a b c$ \\
\hline CNAI10423 & 9 & 100,0 & 9 & 100,0 & 1 & 0 & 7 & 7 & 0 & $19,2 a b c$ \\
\hline CNAI10424 & 9 & 100,0 & 9 & 100,0 & 7 & 0 & 5 & 5 & 5 & $21,0 \mathrm{ab}$ \\
\hline CNAI10425 & 9 & 100,0 & 9 & 100,0 & 5 & 0 & 7 & 5 & 5 & $14,3 a b c$ \\
\hline CNAI10426 & 9 & 100,0 & 9 & 100,0 & 5 & 0 & 7 & 7 & 5 & $11,3 a b c$ \\
\hline CNAI10427 & 7 & 46,3 & 7 & 28,0 & 1 & 0 & 3 & 3 & 1 & $4,6 \mathrm{bc}$ \\
\hline Metica-1 $1^{(6)}$ & 9 & 100,0 & 9 & 100,0 & 7 & 0 & 5 & 5 & 5 & $11,7 \mathrm{abc}$ \\
\hline Patótipo & - & - & - & - & ID-14 & II-1 & IB-1 & IB-1 & IB-45 & - \\
\hline
\end{tabular}

${ }^{(1)}$ Número de entrada no banco ativo de germoplasma da Embrapa-CNPAF. ${ }^{(2)}$ Notas de 0 a 3: resistentes, e notas de 4 a 9: suscetíveis. ${ }^{(3)}$ Severidade de brusone nas folhas. ${ }^{(4)} \mathrm{MtPy}$ : patótipo de Metica-1, CiPy: patótipo de Cica-8, ScmetPy3: patótipo de somaclone de Metica-1, SccicaPy12: patótipo de somaclone de Cica-8, EpPy: patótipo de Epagri 108; notas de 0 a 3: resistentes, e notas de 4 a 9: suscetíveis. ${ }^{(5)}$ Médias seguidas da mesma letra não diferem entre si pelo teste de Tukey a $1 \%$ de probabilidade. ${ }^{(6)}$ Testemunha suscetível, não regenerada. 


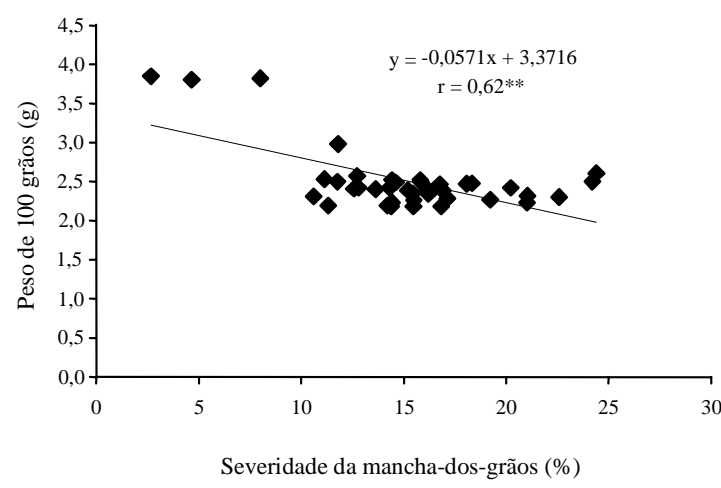

Figura 2. Correlação entre severidade da mancha-dos-grãos e peso de 100 grãos dos somaclones $\mathrm{R}_{6}$ de Metica-1 $(\mathrm{n}=39)$. $* *$ Significativo a $1 \%$ de probabilidade.

Os 38 somaclones estão registrados no Banco Ativo de Germoplasma da Embrapa-CNPAF, como coleção de trabalho do melhorista, incluindo CNAI10390 e CNAI10393, que apresentaram resistência completa e precocidade.

Os objetivos mais importantes do melhoramento genético de plantas são a indução de variabilidade genética e a seleção de plantas com características desejáveis. Embora a maior parte da variabilidade genética necessária para o melhoramento seja proveniente de bancos de germoplasma, o presente estudo permitiu identificar novas fontes de resistência a $P$. grisea até hoje não identificadas no germoplasma mundial.

\section{Conclusões}

1. Os somaclones com resistência específica à brusone desenvolvidos a partir de calos de panículas imaturas de cultivar suscetível podem ser utilizados como novas fontes de resistência no melhoramento de arroz irrigado.

2. Os somaclones mostram variabilidade em relação à resistência à mancha-dos-grãos.

\section{Agradecimento}

Ao sr. Pedro Maurício Machado, pela assistência na realização dos experimentos no campo.

\section{Referências}

ABBASI, F. M.; ABBAS, S. T.; SAGAR, M. A. Evaluation of somaclonal variants for yield and some quality parameters. Pakistan Journal of Scientific and Industrial Research, Karachi, v. 21, n. 1, p. 47-50, 1999.

ARAÚJO, L. G.; PRABHU, A. S. Progresso da brusone nas folhas e características agronômicas nas gerações avançadas de somaclones aromáticos da cultivar de arroz IAC 47. Fitopatologia Brasileira, Brasília, v. 26, n. 3, p. 606-613, 2001.

ARAÚJO, L. G.; PRABHU, A. S.; FILLIPI, M. C. Inheritance of resistance to leaf blast in somaclones of rice cultivar Araguaia. Fitopatologia Brasileira, Brasília, v. 24, n. 2, p. 182-184, 1999.

ARAÚJO, L. G.; PRABHU, A. S.; FILIPPI, M. C.; CHAVES, L. J. RAPD analysis of blast resistant somaclones from upland rice cultivar IAC 47 for genetic divergence. Plant Cell Tissue and Organ Culture, Dordrecht, v. 67, n. 2, p. 165-172, 2001a.

ARAÚJO, L. G.; PRABHU, A. S.; FILIPPI, M. C.; OLIVEIRA, W. F. Variantes somaclonais da cultivar de arroz Bluebelle resistentes à brusone. Pesquisa Agropecuária Brasileira, Brasília, v. 36, n. 5, p. 801-808, maio 2001b.

ARAÚJO, L. G.; PRABHU, A. S.; FREIRE, A. B. Development of blast resistant somaclones of the upland rice cultivar Araguaia. Pesquisa Agropecuária Brasileira, Brasília, v. 35, n. 2, p. 357-367, fev. 2000.

ARAÚJO, L. G.; PRABHU, A. S.; FREIRE, A. B. Variação somaclonal na cultivar de arroz IAC-47 para resistência parcial à brusone. Fitopatologia Brasileira, Brasília, v. 22, n. 2, p. 125-130, fev. 1997.

ARAÚJO, L. G.; PRABHU, A. S.; FREIRE, A. B. Variation for rice blast resistance in early somaclonal generations derived from immature panicles. Pesquisa Agropecuária Brasileira, Brasília, v. 33, n. 8, p. 1349-1359, ago. 1998.

ARAÚJO, L. G.; PRABHU, A. S.; SILVA, G. B. Resistência de somaclones da cultivar de arroz IAC 47 a Monographella albescens. Fitopatologia Brasileira, Brasília, v. 26, n. 2, p. 165-169, 2001c.

BOUHARMONT, J.; DEKEYSER, A.; SINT JAN, V. van; DOGBE, Y. S. Application of somaclonal variation and in vitro selection to rice improvement. In: INTERNATIONAL RICE RESEARCH INSTITUTE (Manila, Filipinas). Rice genetics II. Manila, 1991. p. 271-277. 
CHAUHAN, R. S.; SINGH, B. M.; CHAHOTA, R. K.; DEVELASH, R. K. Generation of indica rice regenerants for resistance to leaf and neck blast. Rice Biotechnology Quarterly, West Lafayette, v. 26, p. 28-29, 1996.

CHOPRA, V. L.; NARASIMHULU, S. B.; KIRTI, P. B.; PRAKASH, S.; ANURADHA, G. Studies of somaclonal variation in Brassica spp. and its relevance to improvement of stress tolerance and yield. In: MUJEEB-KAZI, A.; SITCH, L. A. Review of advances in plant biotechnology, 1985-88. Manila: International Rice Research Institute, 1989. p. 229-238.

CUEVAS-PÉREZ, F. E.; GUIMARÃES, E. P.; BERRIO, L. E.; GONZÁLES, D. I. Genetic base of irrigated rice in Latin America and the Caribbean, 1971 to 1989. Crop Science, Madison, v. 32, n. 4, p. 1054-1059, 1992.

DUVAL, C. M.; CALDAS, L. S.; RESENDE, R. de O. Aplicações da cultura de tecidos na fitopatologia. In: TORRES, A. C.; CALDAS, L. S.; BUSO, J. A. (Ed.). Cultura de tecidos e transformação genética de plantas. Brasília: Embrapa-SPI, 1998. p. 45-68.

EVANS, D. A.; SHARP, W. R.; MEDINA-FILHO, H. P. Somaclonal and gametoclonal variation. American Journal of Botany, Columbus, v. 71, n. 6, p. 759-774, 1984.

FILIPPI, M. C.; PRABHU, A. S.; LEVY, M. Differential compatibility of Pyricularia grisea isolates with some Brazilian irrigated rice cultivars. Fitopatologia Brasileira, Brasília, v. 24, n. 3, p. 447-450, 1999.

FUKUI, K. Sequential occurrence of mutation in a growing rice callus. Theoretical and Applied Genetics, Berlin, v. 65, p. 225-230, 1983.
INTERNATIONAL RICE RESEARCH INSTITUTE (Manila, Filipinas). Standard evaluation system for rice. 3rd ed. Los Baños, 1988. 54 p.

LEUNG, H.; BORROMEO, E. S.; BERNARDO, M. A.; NOTTEGHEM, J. L. Genetic analysis of virulence in the blast fungus Magnaporthe griseae. Phytopathology, St. Paul, v. 78, n. 9, p. 1227-1233, 1988.

MANDAL, A. B.; BIKASH, C.; SHEEJA, T. E.; CHOWDHURY, B. Development and characterization of salt tolerant somaclones in rice cultivar Pokkali. Indian Journal of Experimental Biology, New Delhi, v. 38, n. 1, p. $74-79,2000$.

NOTTEGHEM, J. L. Cooperative experiment on horizontal resistance to rice blast. In: INTERNATIONAL RICE RESEARCH INSTITUTE (Los Baños, Filipinas). Blast and upland rice: report and recommendations from the meeting for international collaboration in upland rice improvement. Los Baños, 1981. p. 43-51.

PRABHU, A. S.; FERREIRA, R. P. Avaliação e seleção no melhoramento de arroz visando resistência a brusone e mancha parda. In: REUNIÓN SOBRE MEJORAMIENTO DE ARROZ EN EL CONO SUR, 1989, Goiânia. Trabajos... Montevidéu: Instituto Interamericano de Cooperación para la Agricultura, 1991. p. 75-85. (PROCISUR. Dialogo, 33).

PRABHU, A. S.; FILIPPI, M. C.; CASTRO, N. Pathogenic variation among isolates of Pyricularia oryzae affecting rice, wheat and grasses in Brazil. Tropical Pest Management, London, v. 38, n. 4, p. 367-371, 1992.

RUEB, S.; LENEMAN, M.; SCHILPEROOT, R. A.; HENSGENS, L. A. M. Efficient plant regeneration through somatic embryogenesis from callus induced on mature rice embryos. Plant Tissue and Organ Culture, Dordrecht, v. 36, n. 2, p. 259-264, 1994. 